\title{
O ENFRENTAMENTO À VIOLÊNCIA NO ÂMBITO DA ESTRATÉGIA SAÚDE DA FAMÍLIA: DESAFIOS PARA A ATENÇÃO EM SAÚDE
}

\author{
Fighting violence under the family health strategy: challenges for health care
}

\section{El afrontamiento de la violencia en la estrategia de salud de la familia: desafíos para la atención en salud}

\author{
Milena da Silva Santos \\ Escola de Saúde Pública do Ceará - ESP - Fortaleza (CE) - Brasil \\ Juliana Guimarães e Silva \\ Universidade de Fortaleza - UNIFOR - Fortaleza (CE) - Brasil
}

July Grassiely de Oliveira Branco

Universidade de Fortaleza - UNIFOR - Fortaleza (CE) - Brasil

\section{RESUMO}

Objetivo: Compreender os desafios enfrentados pelos profissionais da Estratégia Saúde da Familia (ESF) no desenvolvimento da assistência à saúde em áreas vulneráveis à violência. Métodos: Estudo descritivo com abordagem qualitativa, do qual participaram dez profissionais da ESF no município de Aracati, Ceará, Brasil. As informações foram coletadas em março de 2016, por meio de entrevistas semiestruturadas. Após organização e codificação dos dados, seguiu-se a etapa da análise de conteúdo, evidenciando os seguintes fragmentos: Percepções sobre o fenômeno violência; Cuidado em saúde em território de risco; O medo e a resiliência no desenvolvimento da atenção; e Limitações assistenciais e estratégias de enfrentamento à violência. Resultados: O desempenho da assistência à saúde em situações de violência envolve questões de ordem social, físicas e psicológicas. As drogas, o tráfico, a criminalidade, as disputas pelo poder, o tiroteio e a morte permearam o cotidiano dos usuários e dos profissionais da ESF. Entre as principais limitações do cuidado em saúde destacam-se a insegurança e o medo no desempenho do cuidado e as dificuldades de acesso aos domicílios por estarem em área de risco. Conclusão: O desempenho da assistência em áreas vulneráveis à violência representa a exposição dos profissionais a situações adversas, havendo necessidade de resiliência diante das adversidades e, sobretudo, do apoio de gestores e autoridades públicas para que estes possam desenvolver estratégias que facilitem a assistência aos usuários da Atenção Primária inseridos em áreas permeadas pela violência.

Descritores: Assistência à Saúde; Atenção Primária à Saúde; Violência.

\section{ABSTRACT}

Objective: To understand the challenges faced by Family Health Strategy (Estratégia Saúde da Familia - ESF) professionals in delivering health care areas vulnerable to violence. Methods: Qualitative descriptive study carried out with ten ESF professionals in the municipality of Aracati, Ceará, Brazil. Information were collected in March 2016 through semi-structured interviews. Data were organized and coded and then underwent thematic content analysis, which yielded the following fragments: Perceptions of the phenomenon of violence; Health care in a risky territory; Fear and resilience in the delivery of care; and Care limitations and coping strategies for violence. Results: Delivering health care in situations of violence involves social, physical and psychological issues. Drugs, trafficking, crime, power struggles, gunfire and death permeated the daily lives of users and ESF professionals. Some of the main limitations of health care are the insecurity and the fear involved in the delivery of care and the difficult access to the houses located in risk zones. Conclusion: Delivering care in areas vulnerable to violence represents professionals' exposure to adverse situations which require resilience and, above all, support from managers and public authorities so that they can develop strategies to facilitate the delivery of care to Primary Care users inserted in areas permeated by violence.

Descriptors: Delivery of Health Care; Primary Health Care; Violence. 


\section{RESUMEN}

Objetivo: Comprender los desafios afrontados por los profesionales de la Estrategia de Salud de la Familia (ESF) para el desarrollo de la asistencia en salud de áreas vulnerables de violencia. Métodos: Estudio descriptivo de abordaje cualitativo en el cual participaron diez profesionales de la ESF del municipio de Aracati, Ceará - Brasil. Las informaciones fueron recogidas en marzo de 2016 a través de entrevistas semi estructuradas. Después de la organización y codificación de los datos, se dio la etapa del análisis de contenido, en la modalidad temática con la evidencia de los siguientes temas: Percepciones sobre el fenómeno violencia; Cuidado en salud en territorio de riesgo; El miedo y la resiliencia para el desarrollo de la atención; y Limitaciones de la asistencia y estrategias de afrontamiento de la violencia. Resultados: El desempeño de la asistencia en salud en situaciones de violencia incluye cuestiones de orden social, fisicas y psicológicas. Las drogas, el tráfico, la criminalidad, las disputas de poder, el tiroteo y la muerte permearon el cotidiano de los usuarios y de los profesionales de la ESF. Entre las principales limitaciones del cuidado en salud se destacan la inseguridad y el miedo para el desempeño del cuidado y las dificultades de acceso a los domicilios de área de riesgo. Conclusión: El desempeño de la asistencia en áreas vulnerables de violencia representa la exposición de los profesionales para situaciones adversas con la necesidad de resiliencia delante las adversidades y, sobre todo, del apoyo de los gestores y las autoridades públicas para que estes puedan desarrollar estrategias para facilitar la asistencia de los usuarios de la Atención Primaria de áreas permeadas por la violencia.

Descriptores: Prestación de Atención de Salud; Atención Primaria de Salud; Violencia.

\section{INTRODUÇÃO}

A violência se configura como um problema social com forte impacto na saúde. Em 2001, foi incluído o enfrentamento à violência na agenda do setor por meio da Política Nacional de Redução da Morbimortalidade por Acidentes e Violências. De difícil conceituação e caráter polissêmico, a violência é definida nessa política como o evento no qual as ações efetuadas por indivíduos, grupos, classes ou nações provocam danos físicos, emocionais, morais e/ou espirituais a si próprios ou aos outros. Possui igualmente tipologia diversa, sendo a violência criminal e a interpessoal o foco deste estudo( ${ }^{(1)}$.

Ressalta-se que a violência guarda relações profundas com a estrutura social, econômica e política. Aprofunda-se com as exclusões e desproteções sociais, características do atual modelo neoliberal criador de insegurança ${ }^{(2)}$. Inclui-se nesse contexto a Atenção à Saúde e a promoção do cuidado em áreas vulneráveis à violência, comumente caracterizadas por uma infraestrutura precária, em privação de condições materiais de vida e profundas desigualdades sociais. Além das questões sociais, as pessoas que residem no território vivenciam situações de exclusão, a exemplo do desemprego, da falta de saneamento básico, da presença de lixo a céu aberto e da escassez de lazer e seguranç̧a ${ }^{(1,2)}$.

O cuidado em saúde nessas áreas demanda a adequação do serviço à realidade local, o que pode representar inúmeros desafios para sua promoção efetiva. São limitações no acesso à unidade de saúde, insegurança, infraestrutura inadequada, convívio com o tráfico de drogas, entre outros fatores, que tornam o cuidado com a saúde um desafio diário no que toca à sua implementação. No âmbito da Atenção Primária em Saúde (APS), na Estratégia Saúde da Família (ESF), as situações de violência são uma realidade presente em diversas Unidades Básicas de Saúde da Família (UBASF) ${ }^{(3)}$.

Vale lembrar que os processos de trabalho da ESF, em territórios caracterizados por situações de violência, têm sido limitados, pois a violência urbana se faz presente em lugares onde vivem aglomeradas famílias de baixa renda, baixa escolaridade, em situações precárias e desiguais socialmente. O trabalho desenvolvido por profissionais da ESF nessas áreas é inseguro, havendo situações em que só conseguem desempenhar suas atividades no interior das unidades de saúde, restringindo a atenção em saúde somente aos usuários que frequentam as unidades ${ }^{(3)}$.

Estudos sobre o tema ${ }^{(4,5)}$ indicaram que a questão da violência, na qual também se inclui o comércio ilegal de drogas, vêm gerando grande impacto na qualidade de vida das pessoas e pode constituir uma ameaça à integridade física. O comércio de drogas ilegais é preponderante para a violência e condiciona inúmeras situações de conflito entre traficantes e usuários, trazendo inúmeras consequências para a toda sociedade. A violência relacionada ao tráfico de drogas e às relações conflituosas estabelece a complexidade do fenômeno, e as consequências que o tráfico das substâncias ilícitas trazem, como o aumento da criminalidade, se configuram como umas das manifestações da violência ${ }^{(2,5,6)}$.

A violência urbana não é somente composta por dados de letalidade, mas também pelo conflito interpessoal, assaltos à mão armada, agressões, espancamentos e, por fim, os assassinatos ${ }^{(7)}$. Entretanto, a violência não está restrita às agressões físicas e aos homicídios ${ }^{(8)}$, pois observa-se que, cada vez mais, tem afetado a qualidade de vida dos indivíduos, suas famílias e comunidade, gerando diversos problemas físicos, psíquicos, morais e sociais; necessitando, assim, de atenção dos serviços de saúde.

Nos Estados Unidos, a cada ano mais de 30.000 pessoas são mortas por arma de fogo, enquanto 67.000 indivíduos têm algum incidente não fatal relacionado com arma de fogo. O número de incidentes não fatais por arma de fogo aumentou $52 \%$ entre os anos de 1999 e 2012, enquanto os suicídios com armas de fogo aumentaram 17\% entre os anos de 2006 e $2012^{(9)}$.

No Brasil, segundo os registros do Subsistema de Informação sobre Mortalidade do Ministério da Saúde (SIM/MS), entre os anos de 1980 e 2014, morreram 967.851 pessoas vítimas de disparo por arma de fogo. Nesse mesmo período, as vítimas passam de 8.710 , no ano de 1980 , para 44.861 , em 2014 , o que representa um crescimento de $415,1 \%{ }^{(10)}$. A região Nordeste do 
Brasil obteve as maiores taxas de homicídios por arma de fogo (HAF). No ano de 2014, em média, a cada 100 mil habitantes, 32,8 pessoas foram vitimas de HAF. Os estados com os maiores registros são Alagoas, com 56,1 casos, seguido por Ceará, Sergipe e Rio Grande do Norte, com taxas em torno de $40 \mathrm{HAF}$ a cada 100 mil habitantes ${ }^{(10)}$.

Dados epidemiológicos do município de Aracati, Ceará, Brasil, constataram que, no período entre janeiro de 2013 e setembro de 2015, ocorreram 202 casos de violências, dos quais $65(32,1 \%)$ foram provenientes de agressão física, 55 (27,2\%) de objetos perfurocortantes, $56(27,7 \%)$ de arma de fogo, $12(6,0 \%)$ de violência doméstica e 14 (7,0\%) de objeto contundente. Os dados ressaltam que a maioria dos vitimados, 157 (77,8\%), são homens. Houve suspeita de abuso de álcool em 61 (30,1\%) dos casos, e $25(12,3 \%)$ do total de casos evoluíram para o óbito ${ }^{(11)}$.

Diante desse cenário, a relevância do presente estudo para a Promoção da Saúde e para a Saúde Coletiva situa-se no fato de que o cuidado precisa ocorrer de forma condizente com a realidade social da população adstrita para atender suas demandas em saúde. Os números apresentados retrataram uma realidade presente em várias comunidades do município e demandam a compreensão dos desafios e limitações enfrentadas pela equipe multiprofissional durante a atenção em saúde nessas unidades. Busca-se responder: Que tipo de desafios os profissionais da ESF têm enfrentado em relação à violência quando prestam assistência no serviço?

Portanto, objetivou-se compreender os desafios enfrentados pelos profissionais da Estratégia Saúde da Familia (ESF) no desenvolvimento da assistência à saúde em áreas vulneráveis à violência.

\section{MÉTODOS}

Este tipo de estudo, descritivo com abordagem qualitativa, foi escolhido por realizar uma abordagem subjetiva da realidade, permitindo que participantes do estudo descrevam os fenômenos conforme vivenciados ${ }^{(12)}$.

A pesquisa ocorreu no mês de março de 2016, numa UBASF situada no município de Aracati, Ceará, Brasil. A unidade compreende 1.464 famílias cadastradas, com aproximadamente 5.000 pessoas. Atualmente, a equipe de profissionais da ESF é composta por seis profissionais de nível superior e de dezessete de nível médio, e conta ainda com o apoio da equipe do Núcleo de Apoio à Saúde da Família (NASF), composta por fisioterapeutas, assistentes sociais e educadores físicos ${ }^{(13)}$.

O território de abrangência dessa unidade possui graves problemas sanitários, como a presença de lixo espalhado nas ruas e em terrenos baldios, além de ausência de saneamento básico. Concentra-se uma população de baixa renda com predomínio do desemprego. As condições de segurança são precárias, pois não apresenta posto policial e apenas uma equipe Ronda do Quarteirão atende toda a sede municipal.

Participaram deste estudo dez profissionais, dos dezoito que trabalham na unidade, os quais foram selecionados em conformidade com os seguintes critérios de inclusão: fazer parte da equipe de atenção multiprofissional, trabalhar na UBASF por um período mínimo de um ano e consentir em participar livremente do estudo. Foram excluídos os profissionais que estavam em gozo de férias ou licença das atividades laborais.

Inicialmente foi realizada uma visita à coordenação da APS do município, momento em que foram expostos os objetivos da pesquisa e solicitada a autorização para a coleta das informações. Após a autorização da pesquisa, realizou-se uma visita na unidade de saúde, onde se explicou a proposta do estudo aos profissionais e solicitada sua participação.

A coleta das informações ocorreu por meio da aplicação de entrevistas semiestruturadas e individuais, com duração média de 30 minutos, contendo dados de identificação, como idade, sexo, função, tempo de formado, tempo de trabalho na unidade, e questões sobre a dinâmica da assistência à saúde em áreas de risco à violência.

Após a coleta dos dados, os relatos foram transcritos na íntegra e analisados. Como técnica de análise de dados, se utilizou a análise de conteúdo na modalidade temática ${ }^{(12)}$, que consiste em três etapas: a pré-análise, na qual é realizada uma leitura exaustiva dos resultados encontrados; a exploração do material, na qual é desenvolvida uma síntese interpretativa dos resultados dialogando com os objetivos e questionamentos da pesquisa; e a interpretação, momento em que são elencados os aspectos importantes apontados pelo estudo, confrontando-os com a literatura sobre a temática. Assim, emergiram quatro categorias temáticas: Percepções sobre o fenômeno da violência; Cuidado em saúde em território de risco; $\mathrm{O}$ medo e a resiliência no desenvolvimento da atenção; Limitações assistenciais e estratégias do enfrentamento à violência.

Como meio de garantir anonimato dos participantes, atribuiu-se a letra $\mathrm{P}$, referente à profissional, seguido do número de ordem das entrevistas (P.1, P.2..., P.10).

Esta pesquisa foi regida pelos padrões éticos da Resolução n ${ }^{\circ} 466 / 2012^{(14)}$ do Conselho Nacional de Saúde, sendo submetida à apreciação ética e aprovada pelo Comitê de Ética em Pesquisa da Escola de Saúde Pública do Ceará, conforme parecer $\mathrm{n}^{\circ}$ 1407437.

\section{RESULTADOS E DISCUSSÃO}

Serão apresentados inicialmente os dados de identificação dos entrevistados. Em seguida, serão apresentadas as categorias temáticas que emergiram do estudo e que, por meio dos relatos dos entrevistados, permitiram compreender vários aspectos que envolvem a efetivação da assistência à saúde, sobretudo no cotidiano da APS. 


\title{
Dados de identificação dos entrevistados
}

Dentre os dez profissionais da ESF entrevistados que atuavam na UBASF, nove eram do sexo feminino e um do masculino. Quanto à escolariadade, sete tinham nível médio e três tinham nível superior. A média de idade foi de 40,3 anos; e sete deles atuavam na unidade há mais de nove anos. Dos três profissionais com nível superior completo, um possuía especialização em Saúde Pública e dois em Saúde da Família. Esse conhecimento das especificidades da área de atuação e população é fundamental para a prática efetiva da assistência à saúde na Atenção Primária à Saúde (APS) ${ }^{(15)}$.

\section{Percepções sobre o fenômeno da violência}

Nesta categoria, os participantes destacaram suas concepções quanto à violência e seu reflexo na área de atuação da UBASF. Seus relatos revelaram que a violência consiste em um conceito amplo, que pode ocorrer tanto em forma de agressão física, como moral e emocional, conforme se destaca:

\section{“A violência acontece psicologicamente ou fisicamente; ou por contato físico, ou por contato moral” (P.1).}

A violência é um problema social que atinge os indivíduos de forma pessoal e coletiva, trazendo vários problemas para a promoção do cuidado em saúde. Em seu contexto social e histórico, a violência configura-se como um problema de saúde pública, estando relacionada a agravos físicos, emocionais e sociais que influenciam na qualidade de vida dos cidadãos, trazendo consequências para as condições de saúde das pessoas. "Ela consiste no uso da força, do poder e de privilégios para dominar, submeter e provocar danos a outros: indivíduos, grupos e coletividades" (16-23).

Foi marcante entre os profissionais investigados a concepção da violência como intrafamiliar, principalmente quando ocorre por meio de agressões físicas e verbais contra crianças, mulheres e idosos, como destacado nos seguintes depoimentos:
"A violência começa dentro da própria família. Os pais tratam os filhos com agressividade, sem estilo de falar, usando palavrões; então, tudo isso eu considero como violência. A violência física, as agressões, espancamentos, brigas, situações de conflito”(P. 3).
"Acontecem também situações em que marido bate em mulher, maus tratos de crianças e idosos... Às vezes a gente notifica, denuncia, a gente fala para algumas pessoas, mas vêm, olham e vão embora” (P. 8).

Há uma predisposição a situações de conflito no convívio familiar, que podem gerar ações violentas. É comum vivenciar a violência intrafamiliar, sobretudo quando ocorrem as agressões interpessoais contra crianças, mulheres, idosos e deficientes físicos e mentais ${ }^{(1)}$.

Foi possível constatar na atual pesquisa que foram relatadas e notificadas situações de maus tratos contra crianças e idosos, além da violência conjugal. A exposição à violência na primeira infância pode afetar a arquitetura cerebral, o estado imunológico, os sistemas metabólicos e a resposta celular inflamatória, além de contribuir para desenvolver um comportamento prejudicial à saúde durante a fase adulta, como o uso de substâncias ilícitas e comportamento sexual de risco ${ }^{(17,18)}$

Diante dessas consequências, a violência na infância contribui para agravar a saúde dos adultos através dos problemas relacionados à saúde mental e ao desenvolvimento de doenças crônicas, como as doenças cardíacas e o câncer ${ }^{(17,18)}$.

Os participantes da presente pesquisa ressaltaram que a violência urbana está presente em diversos contextos da sociedade, como espaços públicos, ruas, avenidas e instituições. Além disso, observou-se o destaque para a violência na comunidade que, segundo eles, se agravou mediante o aumento de usuários de drogas e do tráfico em áreas da região, o que resultou no convívio da população com assaltos, tiroteio e tráfico de drogas, conforme destacado a seguir:

\begin{abstract}
“A violência está presente em vários locais: no ambiente familiar, nas ruas, nas instituições, nas praças, nas avenidas, em ambientes públicos. Podemos perceber a violência na área da unidade através da dificuldade que a gente encontra em adentrar nas áreas para prestar uma assistência, através da questão das drogas, do uso abusivo de droga. A criminalidade é muito constante na área em que a gente atua. São frequentes os assaltos, tiroteio e comércio de drogas” (P.2).
\end{abstract}

A criminalidade é presente e constante na sociedade brasileira, sobretudo em regiões vulneráveis e nas periferias de grandes cidades. Faz parte desse contexto os assaltos à mão armada, as agressões e os assassinatos, os quais resultam em graves consequências sociais, sendo evidenciados pelo aumento dos índices de violência e da morbimortalidade ${ }^{(4)}$. Essa realidade afeta diretamente a qualidade de vida das pessoas, gerando diversos problemas socioeconômicos que refletem no cotidiano da sociedade $^{(5)}$.

Os cidadãos convivem com as limitações e com as incertezas impostas pela violência. Conforme mencionado, a comunidade convive com o comércio ilegal de drogas ilícitas. As disputas por esse comércio ilegal, bem como as situações de conflitos que envolvem o domínio do tráfico, fazem com que os cidadãos percam a sua liberdade dentro da comunidade e sintam-se coagidos em suas residências, gerando uma diversidade de sentimentos e sensações que afetam consideravelmente suas condições de saúde $^{(3)}$.

Assim, conviver com a violência, além de interferir nas questões socioeconômicas e culturais, faz com que os cidadãos sejam reféns dessa realidade e enfrentem diariamente os riscos provenientes dessa situação como, por exemplo, os assaltos, as 
agressões e principalmente o risco de ser atingido por tiros durante as disputas entre as localidades rivais e, até mesmo, com policiais. Percebe-se que a violência faz parte da experiência humana e pode ser vivenciada de forma interpessoal ou coletiva, ao estar presente no cotidiano de uma comunidade, exercendo ou não influência no contexto econômico, cultural e social da vida humana ${ }^{(19)}$.

\section{Cuidado em saúde em territórios de risco}

Esta categoria objetiva refletir que a APS, através da ESF, configura-se como o primeiro meio de acesso aos serviços de saúde, desenvolvendo atividades de promoção da saúde e prevenção de agravos. O cuidado multiprofissional de assistência à saúde é destinado à população em territórios definidos com o intuito de promover uma atenção integral que contribua para a autonomia e a situação de saúde dessa população ${ }^{(15)}$.

Dessa forma, a ESF tem como prioridade o desenvolvimento de ações que envolvem a comunidade, famílias e indivíduos, no cuidado em saúde, sendo fundamental sua participação nas atividades assistenciais e sociais desenvolvidas nas UBASF. Entretanto, quando a comunidade está vulnerável às situações de violência, o processo de convívio nas unidades fica comprometido, prejudicando a assistência em saúde ${ }^{(3)}$.

Os participantes da presente investigação percebem que os usuários ficam inseguros e têm temor diante da rivalidade entre as comunidades. As drogas, o tráfico, a criminalidade, as disputas pelo poder, o tiroteio e a morte fazem parte do cotidiano dos usuários, conforme destacado em suas falas:

"Percebo através dos pacientes que eles ficam amedrontados, ficam inseguros. Aí, o que acontece: não procuram o posto, com medo, e a gente também, profissional, fica inseguro. É visivel a violência aqui, têm duas comunidades que são rivais" (P. 5).

"Estava até dificil trabalhar aqui na área. Tive que sair correndo, trancar as portas do posto porque estava todo mundo atirando para todo lado. Estava uma verdadeira guerra, estava complicado, era assustador. As pessoas ficavam todas assustadas, entravam gritando, a gente trancava as portas" (P. 6).

Diante dessa realidade, os profissionais, ao atuarem na ESF, estão propensos a enfrentarem situações de conflito e de vulnerabilidade frente a violência ${ }^{(3)}$. Destacaram que vivenciaram inúmeras situações de conflito perto da unidade de saúde, como trocas de tiros entre membros de comunidades rivais, usuários frequentando o posto escoltados e notícias de assassinatos, como referido nas seguintes falas:

"Em uma área que eu trabalho, mataram um rapaz a tiro, dentro de um ponto de comércio, e fazia pouco tempo que eu tinha passado em frente. Ficou até difícil, no decorrer da semana, a gente trabalhar nessa área, devido à rivalidade dessas "gangues". "Eles passavam a todo instante" (P. 10)

Outro estudo também afirma que os profissionais enfrentam situações de violência nos seus locais de trabalho, ressaltando que a maioria dos entrevistados já havia vivenciado situações de violência, como tiros, assaltos e ameaças ${ }^{(20)}$.

Estudo sobre as repercussões da violência urbana na assistência à saúde também indicou resultados semelhantes, pois os profissionais participantes do estudo já haviam enfrentado situações violentas, entre as quais mereceu destaque os confrontos entre os traficantes e policiais que resultaram em tiroteios ${ }^{(6)}$. Ademais, o tráfico de drogas e suas consequências, como ameaças, assaltos e agressões físicas, fazem parte do cenário de atuação dos profissionais de saúde ${ }^{(3)}$.

Outra forma de violência vivenciada na atual pesquisa são os comportamentos agressivos de alguns usuários com os profissionais:

"Fui ofendida algumas vezes, o que é uma violência. A pessoa chega, agride com palavras, chega até a ameaçar, às vezes, se não resolvermos o que ela quer "(P. 6).

Observa-se que a ausência de serviços e a falta de resolutividade da unidade também podem desencadear situações de conflito, que podem ser geradoras de violência, estando o profissional sujeito a agressões verbais, como uso de palavras depreciativas e ameaças. Ressalta-se que usuários insatisfeitos com a assistência fazem, por sua vez, uso do aumento do tom de voz e de xingamentos para atingir o profissional e conseguir o que necessitam ${ }^{(21)}$.

\section{O medo e a resiliência no desenvolvimento da atenção}

Esta categoria denota que os participantes indicaram uma variedade de sentimentos diante da impotência diante da violência presenciada no desempenho da assistência à saúde.

Os sentimentos de aflição, ansiedade e desespero eram presentes em seu cotidiano. Além disso, relataram que enfrentavam o medo nas ruas, no posto de saúde e nos atendimentos em domicílio, como relatado a seguir: 
“As pessoas ficam com medo, amedrontadas, porque são ameaçadas; deixam de sair, ficam em casa” (P. 4).

"A gente tem medo de tudo: tem medo do que fala, se vai sair de casa, se está tendo tiroteio e se não está. Você imagina ter medo do seu próprio semelhante? Interfere demais na vida da gente. Teve gente que adoeceu, ficou doente dos "nervos". Tem gente que se mudou. Um absurdo você ter que se mudar da sua casa porque ninguém resolve o problema” (P.5).

A violência destaca-se, portanto, como um fenômeno que acarreta problemas para as condições de saúde dos usuários e dos profissionais, como também interfere no desempenho profissional dos trabalhadores que realizam assistência nesses ambientes adversos. Conforme citado por uma das participantes:

“Convivendo com isso a gente está adoecendo e se afastando das atividades de trabalho” (P. 7).

Essa realidade adversa pode gerar problemas no desempenho profissional, absenteísmo e alterações psicológicas nos trabalhadores ${ }^{(22,23)}$.

Transcendendo as limitações apresentadas, emerge a capacidade de resiliência do profissional de saúde diante dos desafios de promover o cuidado em saúde em áreas vulneráveis à violência. Os participantes destacaram que, apesar dos desafios enfrentados no desempenho do cuidado, conseguiam reunir forças e desempenhar a assistência em saúde. Esses profissionais enfrentavam um processo contínuo de adaptação a uma nova realidade de trabalho, permeada por uma diversidade de sentimentos, apoiando-se em sua capacidade de resiliência e enfrentando seus medos e anseios para continuar desempenhando seu trabalho, como pode ser visto a seguir:

\begin{abstract}
"Mesmo com medo, com as dificuldades no atendimento e a insegurança que enfrentamos aqui na unidade, toda a equipe se une e tenta atender os usuários da melhor forma possivel. A gente faz o possivel para esse atendimento ser agilizado, ser mais rápido. As queixas deles serem resolvidas para poderem ir embora e não terem nenhum problema, nem com eles nem com a gente que está atendendo. [...] Nessas horas temos que ter coragem de enfrentar essa realidade e continuar atendendo" (P. 4).
\end{abstract}

Os seres humanos possuem a capacidade de superar as adversidades da vida. Quando expostos a conflitos que envolvem violência, podem transformar as ações, superando as adversidades impostas. Assim, realizar o cuidado em saúde envolve a capacidade de enfrentar as dificuldades e de reestruturar-se diante das adversidades encontradas no universo assistencial ${ }^{(20)}$.

\title{
Limitações assistenciais e estratégicas de enfrentamento à violência
}

Foi possível constatar no presente estudo como a violência interfere no processo de trabalho da unidade de saúde na medida em que a equipe não consegue realizar os cuidados assistenciais de acordo com o cronograma de atendimentos e também não desempenha a assistência domiciliar em algumas áreas de risco.

Os participantes enfrentavam diariamente diversos desafios, os quais, por vezes, limitavam sua prática profissional. Dentre eles, o medo de confronto das comunidades rivais, de conviver com usuários de drogas ilícitas e com o tráfico de drogas. Assim, os profissionais ficavam desmotivados para promover ações dentro da comunidade, ficando restritos somente no espaço físico da UBASF.

Indicaram que, entre as limitações assistenciais impostas pela vulnerabilidade à violência, estão: a dificuldade de acesso aos domicílios em área de risco; a dificuldade de locomoção da equipe; a fragilidade diante de ameaças físicas; a dificuldade em conseguir a confiança da população de uma área de risco; a diminuição da frequência da população ao posto por causa da violência.

"Dificuldade em adentrar as áreas pra prestar uma assistência, questão das drogas, do uso abusivo de drogas, a criminalidade é muito constante na área a qual a gente atua. Atrapalha muito a nossa assistência, os trabalhos que podem estar sendo realizados na comunidade” (P.1).

"Eu acho que a dificuldade é você conseguir chegar até a área. É você conseguir confiança na área que você vai atuar e estar ocorrendo o problema” (P.3).

Outros estudos também constataram as limitações que a violência ocasiona no desempenho da assistência apresentando resultados semelhantes. O estudo dos autores mostra que uma enfermeira destaca que o atendimento em saúde, tanto no posto de saúde como no domiciliar, ficava comprometido quando tinha tiroteio na área, o que nos leva a inferir as limitações que a violência impõe no cuidado em saúde ${ }^{(3)}$.

A violência interfere no desempenho da assistência à saúde por provocar limites no acesso ao serviço, fazendo com que a população não compareça à unidade e, da mesma forma, os profissionais não conseguem desenvolver uma assistência domiciliar $^{(24)}$. O acesso ao atendimento domiciliar, por questões de interferência da violência, não se consegue realizar com qualidade para os usuários ${ }^{(25)}$. Evidenciou-se que o trabalho dos ACS ficou limitado frente à violência vivenciada na área, como observado no seguinte relato: 
"É de estar trabalhando e ter que ir embora, não realizar meu trabalho por conta de confusão entre uma comunidade e outra através do tráfico. Eu já tive de voltar da área por acontecer tiros e eu não poder ficar para trabalhar e ter que ir embora. [...] A gente não poder fazer o trabalho que a gente queria que fosse realizado... Eu comecei a observar que nem toda hora eu poderia entrar na minha área. Às vezes, não dá para realizar as visitas. Quem sofre mesmo são os idosos, as crianças, as puérperas que precisam de uma atenção especial, e nós não podemos ir por conta dessa violência”" (P. 9).

O trabalho dos ACS é fundamental para elaboração do cuidado em saúde na atenção primária. São eles que fortalecem o vínculo entre a unidade de saúde e usuários, identificam os principais problemas e promovem ações preventivas nos domicílios. Quando não conseguem frequentar assiduamente a área, suas atividades ficam limitadas e quem sofre as consequências são os usuários que não recebem a assistência de que necessitam.

Ressalta-se que a violência na comunidade dificulta o trabalho na medida em que causa a sensação de medo e ansiedade, restringe o acesso em algumas áreas, e que o risco de violência se agrava ${ }^{(3)}$. Profissionais de saúde, durante a realização de visitas domiciliares, estão vulneráveis à situações de violência como o convívio com o tráfico, tiroteios, assaltos e intimidação pessoal $^{(26)}$.

Algumas ACS também referiram que, apesar de enfrentarem situações de risco, conseguem realizar seu trabalho nos domicílios, conforme demonstrado nas falas a seguir:

\begin{abstract}
"Mesmo com a violencia acontecendo, eu chegava e fazia meu trabalho. Eu tive que mostrar pra eles que realmente eu estava ali porque gostava do trabalho e para servir a eles. Era bem recebida por eles, então o risco que eu corria era se acontecesse um conflito entre eles que estavam brigando e eu fosse atingida" (P. 7).

“A gente tenta trabalhar naturalmente, tenta não passar medo, essas coisas, porque até os vizinhos deles já estão com medo, ai a gente não vai se mostrar com medo também, a gente tem que superar e ser mais forte para poder enfrentar isso" (P. 8).
\end{abstract}

Essa realidade ocorre pelo fato do profissional possuir a confiança da comunidade e também por morar na área de atuação, possuindo, assim, uma maior familiaridade com a realidade da comunidade, sentindo-se mais confortáveis no desenvolvimento do cuidado em saúde ${ }^{(27)}$. Entretanto, é importante ressaltar que esses profissionais convivem com a violência, tanto por ser profissional de saúde quanto por ser morador da área de risco, o que ocasiona um processo de enfrentamento à violência, como algo que faz parte de sua rotina, tanto nos aspectos pessoais quanto profissionais.

Outros fatores destacados pelos participantes foram referentes às questões que envolvem a infraestrutura inadequada da área, como: falta de lazer, desemprego, deficiência de saneamento básico, exposição de lixo, falha na segurança pública e ambiente inapropriado para assistência no território, conforme destacado no discurso a seguir:

“As dificuldades são muitas. São pessoas muito carentes, que precisavam ter um suporte melhor. [...] São muitos desempregados, não existe um lazer adequado. Eles não têm saneamento, o lixo é nas ruas, é inseguro, lá ainda é areia, os quintais tudo aberto, ainda existem casas sem banheiro. [...] Falta um atendimento adequado, um local para realizar o atendimento aqui na área" (P.8).

A atenção primária ainda não possui financiamento suficiente do setor saúde. As condições de trabalho e socioeconômicas ainda são precárias em muitos lugares, dificultando a realização de uma assistência humanizada, corroborando com os fatores elencados pelos participantes ${ }^{(15)}$. Diante dessa realidade, as equipes de saúde pública devem identificar os cenários de violência e desenvolver meios de atuação nessa realidade ${ }^{(4)}$.

Os entrevistados indicaram que, quando ocorreram situações que envolviam risco para os usuários e profissionais, os atendimentos na unidade de saúde foram reagendados. Foi ressaltado que, nos dias em que ocorriam os tiroteios ou ameaças, a comunidade não frequentava a unidade por medo de alguma violência, como destacado na seguinte fala:

"A gente procura colocar dias diferentes, pra que essas pessoas venham ao posto e não venham correr o risco de se encontrarem, das duas áreas. Ficou dificultoso quando estava em conflito, era muito difícil a gente conseguir ir pra comunidade. Pelo contrário, algumas pessoas da comunidade vinham à unidade para dizer para a gente não ir porque não tinha como a gente ir, por medo de bala perdida" (P. 2).

Constatou-se, portanto, que, apesar das dificuldades apresentadas, a assistência era realizada tomando-se algumas precauções, como o agendamento por microáreas, priorizando a divisão das áreas em conflito para que os atendimentos não ocorram no mesmo dia, além de contato com a comunidade para agendamento dos atendimentos, para que se possa realizar o atendimento no posto e domiciliar.

Um fator relevante apontado pelas profissionais foi a importância de conquistar a confiança da comunidade para que se possa realizar o cuidado em saúde.

"Temos que tentar reunir as pessoas das duas áreas para a gente tentar conversar, pra que, por meio disso, a comunidade não sofra e não deixe de receber atendimento" (P. 2). 
Conversar com as duas áreas sobre a violência e como está afetando a qualidade dos atendimentos é fundamental para elaboração de ações que permitam enfrentar essa realidade e desenvolver a assistência.

Para tanto, durante a assistência, a equipe de saúde deve se mostrar comprometida com o usuário através de uma postura empática diante de suas necessidades, para que seja possível compreender as reais necessidades da população na área de abrangência ${ }^{(15)}$. Esse vínculo de confiança só se consegue através de estratégias que promovam um acolhimento qualitativo e empático ao usuário, para que ele se sinta seguro no cuidado em saúde ${ }^{(28)}$.

Diante da violência intrafamiliar, os profissionais de saúde da APS podem notificar essas ocorrências por meio do Sistema de Vigilância de Violências e Acidentes (VIVA), permitindo conhecer a realidade e elaborar estratégias de intervenção ${ }^{(29)}$, conforme ressaltado no trecho a seguir:

"Quando presenciamos situações de violência na família e maus tratos, devem ser realizadas as notificações para podermos intervir" (P.1).

Referente às questões da violência urbana e das disputas no cenário do tráfico de drogas, os participantes destacaram que é necessário manter o diálogo com a comunidade para enfrentar essa realidade, abordando questões como: sugestões comunitárias que facilitem o acesso ao serviço de saúde, questionamentos sobre os fatores que condicionam os jovens da comunidade a entrarem no universo do tráfico, elaboração de estratégias que facilitem o diálogo entre as duas áreas de conflito, e promoção de esclarecimentos sobre a importância do atendimento em saúde para a população.

"O primeiro passo para se conseguir trabalhar com essas pessoas, nessas áreas, é a equipe sair do consultório e atuar mais na área, dando mais assistência lá, com abordagens educativas, com atividades preventivas mais que curativas. Tentar incluir essas pessoas na sociedade, porque, por exemplo, uma área que a gente trabalha aqui, você chega lá, você sente as pessoas totalmente excluidas de tudo" (P. 3).

A ESF, por sua proximidade com a comunidade, possui um papel relevante no enfrentamento à violência, sobretudo na prática de atividades em educação em saúde. Uma ferramenta de enfrentamento em situações de violência. Através da educação é possível conhecer as características da realidade imposta, orientar os moradores e estabelecer vínculos com a comunidades, que são importantes para o enfrentamento à violência na assistência à saúde ${ }^{(20)}$.

A violência não se relaciona apenas ao tráfico de drogas e suas consequências. Está presente no cotidiano da vida humana, podendo surgir por questões estruturais, decorrentes da sobreposição de privações e segregação social que acaba por impactar negativamente na atenção à saúde.

Os participantes enfatizaram a importância da promoção de ações de educação em saúde para os jovens e adolescentes da comunidade, como: promover abordagens educativas, debates, mesas redondas e oficinas, nas escolas e comunidade, juntamente com os professores, sobre a temática drogas ilícitas, destacando o incentivo ao esporte e lazer e programas de primeiro emprego, como se observa em seus relatos:

"Deve ter mais incentivo ao emprego, à profissionalização, e oferecer espaço para esses jovens no esporte, música, lazer; ocupar a mente deles” (P. 7).

"Discutir mais nos colégios a respeito do uso de drogas. Usar estratégias de educação em saúde sobre drogas e pedir ajuda no colégio, juntamente aos professores, para abordarem mais esses assuntos [...] Fazer projetos educativos, como esportes." (P. 10).

Para isso, é necessário que ações intersetoriais sejam bem articuladas, tendo em vista que as ações de prevenção à violência, quando ocorrem de forma integrada, através de ações desempenhadas em diversos setores sociais, possuem mais êxito se comparadas com ações de caráter individual ${ }^{(6)}$.

Deve-se promover uma ação conjunta envolvendo as Secretarias de Ação Social, de Educação de Esporte e Lazer e de Saúde, para que assim possam diagnosticar os problemas da comunidade e, a partir dessa realidade, elencar as prioridades, elaborando intervenções que melhorem o acesso à saúde e qualidade de vida dos usuários.

As limitações do presente estudo se relacionaram à realização da pesquisa em apenas uma unidade de saúde, haja vista que realizar a pesquisa em outras permitiria uma compreensão ampliada acerca das limitações impostas pela violência no desempenho da assistência à saúde.

Emerge, portanto, a necessidade da implementação de estratégias de intervenção em caráter multissetorial, que propiciem a realização dos cuidados necessários para a população, sobretudo para as que residem em áreas nas quais são vivenciadas as disputas do tráfico.

\section{CONSIDERAÇÕES FINAIS}

A violência se apresentou como um reflexo de todo o contexto socioeconômico vivenciado pela comunidade, a qual convive com o desemprego, a ausência de políticas públicas, a falta de infraestrutura, a falta atividades culturais e lazer, além de diversos problemas sanitários. 
A criminalidade foi um fator amplamente relatado pelos participantes. Constatou-se que as drogas, o tráfico, as disputas pelo poder, o tiroteio e os assassinatos faziam parte do cotidiano dos usuários e dos profissionais da ESF. As principais limitações do cuidado em saúde destacadas pelos participantes foram a insegurança e o medo no desempenho da assistência e as dificuldades de acesso aos domicílios em área de risco.

Concluiu-se que desempenhar a assistência em áreas vulneráveis à violência significa o convívio com situações adversas, havendo a necessidade de resiliência diante das adversidades e, sobretudo, do apoio de gestores e das autoridades públicas para que os profissionais possam desenvolver estratégias que facilitem a assistência aos usuários da APS, inseridos em áreas permeadas pela violência.

Assim, o desenvolvimento de estratégias de cuidado que promovam uma amplitude da assistência à saúde é necessária e urgente para essa população, haja vista os problemas socioeconômicos, culturais e sanitários enfrentados.

\section{REFERÊNCIAS}

1. Minayo MCS, Souza ER. Violência sob o olhar da saúde: a infrapolítica da contemporaneidade brasileira. $2^{\mathrm{a}}$ ed. Rio de Janeiro: Fiocruz; 2011.

2. Larsen DA, Lane S, Jennings-Bey T, Haygood-ElA, Brundage K, Rubinstein RA. Spatio-temporal patterns of gun violence in Syracuse, New York 2009-2015. PLoS One. 2017;12(3):1-10.

3. Polaro SHI, Gonçalves LHT, Alvarez AM. Enfermeiras desafiando a violência no âmbito de atuação da Estratégia de Saúde da Família. Texto \& Contexto Enferm. 2013;22(4):935-42.

4. Mikton CR, Tanaka M, Tomlinson M, Streiner DL, Tonmyr L, Lee BX, et al. Global research priorities for interpersonal violence prevention: a modified Delphi study. Bull World Health Organ. 201795(1):36-48.

5. Lopes CS, Moraes CL, Junger WL, Werneck GL, Ponce de Leon AC, Faerstein E. Direct and indirect exposure to violence and psychological distress among civil servants in Rio de Janeiro, Brazil: a prospective cohort study. BMC Psychiatry. 2015;15(109):1-9.

6. Machado CB, Daher DV, Machado CB, Daher DV. Violência urbana: repercussões e consequências na assistência à saúde em uma Unidade de Saúde da Família. Ciênc Cuid Saúde. 2016;14(4):1445-52.

7. Moura LBA, Oliveira C, Vasconcelos AMN. Violências e juventude em um território da Área Metropolitana de Brasília, Brasil: uma abordagem socioespacial. Ciênc Saúde Coletiva. 2015;20(11):3395-405.

8. Ribeiro WS, Mari JJ, Quintana MI, Dewey ME, Evans-Lacko S, Vilete LM, et al. The impact of epidemic violence on the prevalence of psychiatric disorders in Sao Paulo and Rio de Janeiro, Brazil. PLoS One. 2013;8(5):63545.

9. Fowler KA, Dahlberg LL, Haileyesus T, Annest JL. Firearm injuries in the United States. Prev Med. 2015;79:5-14.

10. Waiselfisz JJ. Mapa da violência 2016: homicídios por arma de fogo. Rio de Janeiro: FLACSO/CEBELA; 2016.

11. Sistema de Informação de Agravos de Notificação - SINAN. Dados epidemiológicos. Aracati: Secretaria Municipal de Saúde; 2016.

12. Minayo MCS. O desafio do conhecimento: pesquisa qualitativa em saúde. 12a ed.. São Paulo: Hucitec, Abrasco; 2010.

13. Sistema de Informação da Atenção Básica - SIAB. Equipes Unidades Básicas de Saúde da Família. Aracati: Secretaria Municipal de Saúde; 2016.

14. Brasil. Resolução CNS no 466/12 Conselho Nacional de Saúde. Diretrizes e normas regulamentadoras de pesquisas envolvendo seres humanos [acesso em 2016 Mar 2]. 2012. Disponível em: http://conselho.saude.gov.br/resolucoes/2012/ Reso466.pdf.

15. Ministério da Saúde (BR), Secretaria de Atenção à Saúde, Política Nacional de Humanização da Atenção e Gestão do SUS. Clínica ampliada e compartilhada. Brasília: Ministério da Saúde; 2009.

16. Minayo MCS. Conceitos e tipologias de violência: a violência faz mal à saúde. In: Najine K, Assis SG, Constantino P. Impactos da violência na saúde. $2^{\mathrm{a}}$ ed. Rio de Janeiro (RJ): Fiocruz; 2009. p. 21-42.

17. Bellis MA, Lowey H, Leckenby N, Hughes K, Harrison D. Adverse childhood experiences: Retrospective study to determine their impact on adult health behaviours and health outcomes in a UK population. J Public Health (Oxf). 2014;36(1):81-91.

18. Danese A, McEwen BS. Adverse childhood experiences, allostasis, allostatic load, and age related disease. Physiol Behav. 2012;106(1):29-39. 
19. Ferreira VP, Silva MA, Noronha C Neto, Falbo GH Neto, Chaves CV, Bello RP. Prevalência e fatores associados à violência sofrida em mulheres encarceradas por tráfico de drogas no Estado de Pernambuco, Brasil: um estudo transversal. Ciênc Saúde Coletiva. 2014; 19(7):2255-64.

20. Costa JV, Piber LD. Compreensões do fenômeno violência: A voz dos profissionais da atenção básica em saúde do Bairro Nova. Anais Congresso Estadual de Teologia. 2016; 1(1):458-466.

21. Fontes KB, Santana RG, Pelloso SM, Carvalho MDB. Fatores associados ao assédio moral no ambiente laboral do enfermeiro. Rev Latinoam Enferm. 2013; 21(3):758-64.

22. Vasconcelos SC, Souza SL, Sougey EB, Ribeiro ECO, Nascimento JJC, Formiga MB, et al. Nursing staff members mental's health and factors associated with the work process: an integrative Review. Clin Pract Epidemiol Ment Health. 2016;12:167-76.

23. Vasconcellos IRR, Abreu AMM, Maia EL. Violência ocupacional sofrida pelos profissionais de enfermagem do serviço de pronto atendimento hospitalar. Rev Gaúch Enferm. 2012;33(2):167-75.

24. Silva LO L, Dias CA, Soares MM, Rodrigues, SM. Acessibilidade ao serviço de saúde: percepções de usuários e profissionais de saúde. Cogitare Enferm. 2011;16(4):654-60.

25. Leão LO, Dias CA, Soares MM, Rodrigues SM. Acessibilidade ao serviço de saúde: percepções de usuários e profissionais de saúde. Cogitare Enferm. 2011;16(4):654-60.

26. Lisboa MTL, Vasconcellos IRR, Griep RH, Araújo CM. Riscos ocupacionais em um serviço de visita domiciliar. Anais ABEn. 2013;1(1):1120-2.

27. Kebian LVA, Acioli S. A visita domiciliar de enfermeiros e agentes comunitários de saúde da Estratégia Saúde da Família. Rev Eletrônica Enferm. 2014;16(1):161-9.

28. Vilela SDC, Carvalho AMP, Pedrão LJ. Relação interpessoal como forma de cuidado em enfermagem nas estratégias de saúde da família. Rev Enferm UERJ. 2014;22(1):96-102.

29. Ministério da Saúde (BR), Secretaria de Vigilância em Saúde, Departamento de Vigilância de Doenças e Agravos não Transmissíveis e Promoção da Saúde. Sistema de Vigilância de Violências e Acidentes (Viva): 2009, 2010 e 2011 . Brasília: Ministério da Saúde; 2013.

\section{Endereço para correspondência:}

Milena da Silva Santos

Rua Beira Rio, 1868.

Bairro: Pedra Redonda

CEP: 62.800-000 - Aracati - CE- Brasil

E-mail: mylenasantos19@hotmail.com 